\title{
Associated factors for cognition of physically independent elderly people living in residential care facilities for the aged in Sri Lanka
}

Madushika Wishvanie Kodagoda Gamage ${ }^{1}$, Chandana Hewage ${ }^{2^{*}}$ and Kithsiri Dedduwa Pathirana ${ }^{3}$

\begin{abstract}
Background: As the elderly population and prevalence of dementia is increasing, it is necessary to have a better comprehension of the influence of specific factors on cognitive function. Dementia is not an inevitable consequence of ageing. Lifestyle factors might either increase or decrease the risk. Even though different studies have focused on individual factors, only a few studies are available which assess all these factors as a whole. Available evidence on these factors is mainly from high income countries and much less evidence is available from low and middle income countries. As cognition is critical for elderly people to engage in a physically independent life, we aimed to identify the associated factors of cognition.
\end{abstract}

Methods: This was a descriptive cross sectional study performed with 421 elderly people dwelling in residential care facilities for the aged in two selected districts in the Southern Province of Sri Lanka. Cognition was assessed using the Mini Mental State Examination (MMSE). Independent sample t test, ANOVA and regression analyses were used to explore associated factors for cognition. The statistical significance was kept at bonferroni adjusted $p<0.004$.

Results: The study included elderly people with a mean age of $71.9 \pm 6.7$ years and of them $65.8 \%$ were females. Factors affecting higher level of cognition were, having upper secondary, advanced and higher education; being married; arriving at the facility on one's own accord; being visited by family members; higher physical activity levels and engaging in social and leisure activities $(p<0.004)$. The factors, namely physical activity level, educational status, visits by family members and engaging in leisure activities were the predictors of cognition in the regression model.

Conclusion: Though there were several factors that associated with the level of cognition such as educational status, marital status, reason for attending the facility, visits by family members, physical activity levels and participation in social and leisure activities, only the factors, such as physical activity levels, visits by family members, educational status and engaging in leisure activities were the predictors of cognition.

Keywords: Elderly people, Cognition, Associated factors

\footnotetext{
* Correspondence: dchewage@sjp.ac.lk

2Department of Physiology, Faculty of Medical Sciences, University of Sri

Jayewardenepura, Gangodawila, Nugegoda, Sri Lanka

Full list of author information is available at the end of the article
}

(c) The Author(s). 2019 Open Access This article is distributed under the terms of the Creative Commons Attribution 4.0 International License (http://creativecommons.org/licenses/by/4.0/), which permits unrestricted use, distribution, and reproduction in any medium, provided you give appropriate credit to the original author(s) and the source, provide a link to the Creative Commons license, and indicate if changes were made. The Creative Commons Public Domain Dedication waiver (http://creativecommons.org/publicdomain/zero/1.0/) applies to the data made available in this article, unless otherwise stated. 


\section{Background}

Population ageing, an increase in numbers of those aged 60 years and above, is a worldwide twenty-first century phenomenon [1]. This occurs due to two derivatives; increasing longevity and decrease in fertility [2]. The definition of ageing itself is arbitrary. Ageing is a biological reality which holds its own dynamic away from human control [3]. With an increase in the world's ageing population, the number of elderly people living with dementia is also in an upward trend. This figure is projected to rise more in low and middle income countries [4].

Dementia is a progressive disorder affecting memory, other cognitive abilities and behaviour and it is the greatest global challenge in the twenty-first century [5]. Dementia is not an inevitable consequence of ageing [6]. Decline in cognitive functions with ageing is similar to other health characteristics, such as sensory and musculoskeletal functions. Cognitive functions begin to decline at a comparatively young age, and different functions decrease at different rates [3]. Cognition is a process, by which "sensory inputs are transformed, reduced, elaborated, stored, recovered and used" [7]. Cognitive impairment can be either due to normal ageing process or due to disease conditions relating to neuroanatomical, biochemical or electrophysiological changes in the brain [8]. Cognitive health promotion, that is, to maintain "brain health" with ageing has become more and more vital for the elderly [9]. But, for planning and preventive/intervention measures, identification of specific elements that may underlie cognitive decline is essential. Life style factors may modify the risk of development of dementia [6].

Though different studies have concentrated on individual factors, few studies are available which assess the factors as a whole. Positive relationship between physical activity and cognition is well addressed by many authors $[10,11]$. In addition, many other factors have been assessed individually. Most of the researchers have focused their attention on the individual factors, such as age [12] and educational status [13]. A few studies have assessed the impact of marital status [14], leisure activities [15, 16], social activities [17] and sleep [18] on cognition. However, in studies, the findings were not consistent. For example, some evidence suggests that women have less age-associated cognitive decline [19] and more resilience to age-related cognitive decline than men [20], while others show more cognitive loss in females than men in the community [21] and institutions [22].

Available evidence on risk factors for dementia are mainly from high income countries and less evidence is available from low and middle income countries [6]. In Sri Lanka, population ageing is observed [2]. According to Sri Lankan norms, elderly people are looked after by their children and family members and it was longly existed [2]. However, as a result of socio demographic changes and changes in family system such as increasing number of employed women, decreasing number of children and conversion of family system from extended to nuclear families, the care for the elderly people are reducing [2]. As a result, the number of elderly people living in aged care facilities is increasing [2]. Meals, lodging, recreation, protection and other facilities for the residents are provided free of charge through different sources of funding [23]. There are caregivers in these facilities but they are not adequately trained for the purpose. Cognitive functions are particularly important for elderly people in residential care facilities as they need to have physical independence without family support.

The level of cognition and its associated factors will be different for elderly people in residential care facilities for aged compared to elderly people in the community, due to divergence in living arrangements. Previous studies have mainly focused their attention on community dwelling elderly populations $[17,20,21]$. With the growth of population ageing leading to increased demand for long term care facilities, it would be necessary to understand the combined effect of different factors rather than individual effects on their cognitive functions. It has been shown that cognitive decline is linked with physical dependency and poor quality of life [24]. Some associated factors will be modifiable factors; hence, identification of such factors will help health care professionals to use them in planning therapeutic measures to preserve cognition in the elderly.

\section{Methods}

\section{Study design and setting}

This was a descriptive cross sectional study. Participants were selected from the residential care facilities for aged in Galle and Matara Districts in Southern Province, Sri Lanka. Most of the residential aged care facilities are situated in Western and Southern provinces. In Sri Lanka, elderly people admitted to residential care facilities mainly due to socio economic issues [23].

\section{Recruitment of subjects}

Subjects were recruited using probability proportional to size sampling technique. First, an aged care facility was selected randomly and then, all the elderly people in that facility was screened for selection criteria. Among them, those who fulfilled the criteria and who volunteered to participate were recruited as the study sample. Method of recruitment has previously decribed in Gamage, Hewage and Pathirana [23]. The number of subjects recruited for this part of the study was 421 as shown in Fig. 1.

The sample for the analysis consisted of 421 individuals, aged 60 years and above. Participants who had psychiatric disorders, severe cognitive impairment, severe 


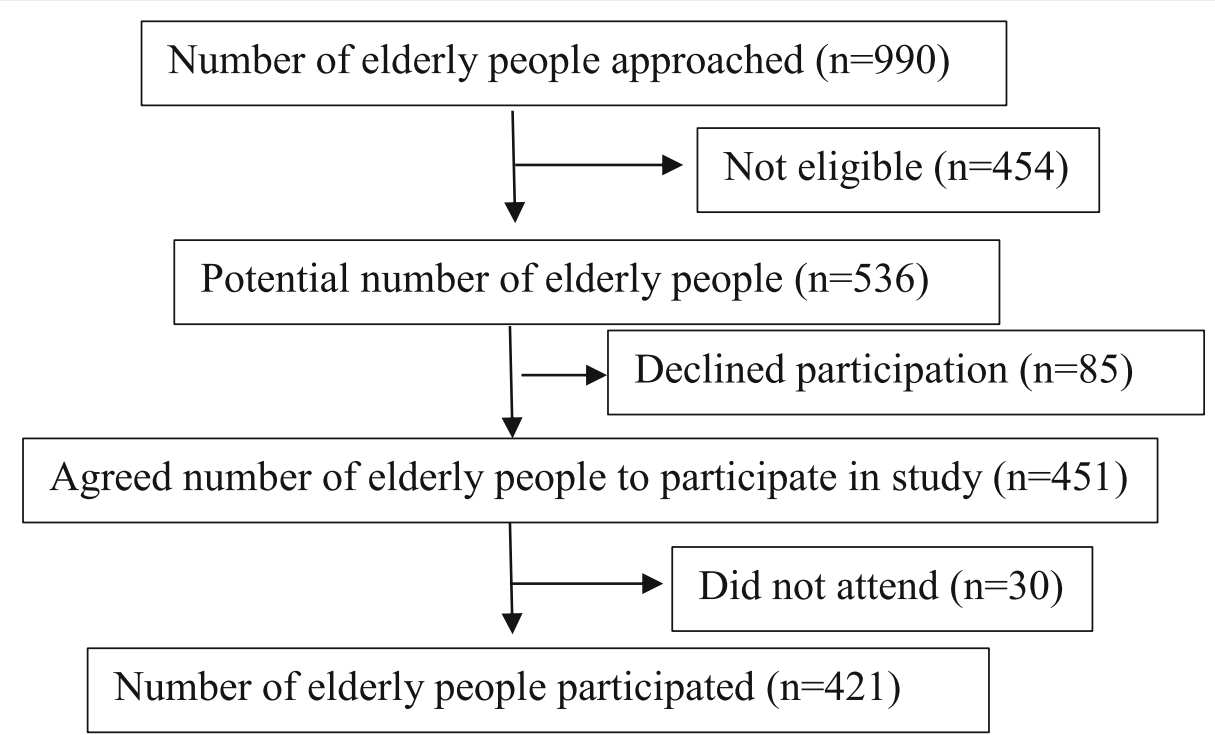

Fig. 1 Recruitment of subjects to the study. The process of recruitment of study subjects is shown. The number of subjects approached, which was not eligible, who declined participation, who did not attend and the number of subjects who participated to the study are shown

untreated vision or hearing loss and neurological and musculoskeletal disorders were excluded. Psychiatric disorders refer to any mental disorder diagnosed by a psychiatrist such as depression, bipolar affective disorder and schizophrenia. Neurological disorders refer to disorders of the nervous system diagnosed by a neurologist that affects test performance such as stroke and aphasia. Musculoskeletal disorders were the disorders in the musculoskeletal system diagnosed by a medical officer that affects test performance such as osteoarthritis, fractures and amputations. Presence of these disorders was confirmed by using health records of the participants. Those who have corrected vision worse than $6 / 60$ were considered as having severe vision loss. Hearing loss was interviewer rated. Selected subjects were physically independent elderly people based on the score of Barthel's index.

\section{Cognitive performance- mini mental state examination (MMSE)}

The MMSE is a widely used and well-known questionnaire to screen cognitive impairment [25]. It is a 30 point scale and assesses five areas; orientation, registration, attention and calculation, recall and language. A score of less than 11 was considered as having severe cognitive impairment [26].

\section{Demographic and other factors}

A pretested self-developed questionnaire was used to obtain data on demographic characteristics, presence of chronic diseases, BMI, sleep duration, presence of sleep disturbances, reason for attending facility, visits by family members and participation in leisure and social activities. One of the authors who is a registered nursing officer in Sri Lanka interviewed the subjects. Informant was used to confirm the information given by the participants.

Age, gender, educational status and marital status were asked from the participants. Age was confirmed using the participants' identity card. Information such as presence of chronic diseases was sourced using the medical records they had. Height and weight of the participants was measured to calculate BMI. Score was categorized based on the recommended BMI cut off scores for Asian populations [27]. The number of sleeping hours participants had at night and presence of sleep disturbances was inquired from the participants.

The reason for attending the facility was considered as two factors. Whether the participants chose to admit themselves to pursue a more leisurely life away from family responsibilities and work, or whether they were compelled to be admitted due to lack of available care at home, migration of family or familial discord. Visits by family members accounted as revealed by subjects whether family members come to the facility to visit them or not.

\section{Social and solitary leisure activity participation}

Adams, Leibbrandt and Moon mentioned, theoretically any activity can be grouped as either social or solitary activities [28]. Solitary activities included the activities that one does alone while social activities included activities done in groups. We considered the activities engaged during the past month. First, individual activities were considered and then they were allocated into types. We considered four types of solitary leisure activities 
$[29,30]$ as engagement in mental; i.e. reading books, chanting religious versus, physical; i.e. gardening and performance of exercises, productive; i.e. craft work and recreational activities; i.e. watching television, listening to radio programmes. Social activity participation included the participation in four types of activities [17] as voluntary work, social interactions, participation in community related organizations and participation in activity groups.

\section{Physical activity}

The International Physical Activity Questionnaire modified for Elderly (IPAQ-E) was used to determine the level of physical activity. It provides continuous scores as well as categorical values. Based on their physical activity score, participants were categorized as inactive, minimally active and as having health enhancing physical activity (HEPA) level [31].

\section{Statistical analysis}

Statistical analysis was performed using SPSS 20.0 version. Frequencies, means and standard deviations of the variables were calculated. The normality of the data was assessed. Independent sample $t$ test and ANOVA were used. Factors that showed a significant association were used in the regression analysis. Multicollinearity was assessed using correlation analysis (r). Variance inflation factor (VIF) between variables and Durbin-Watson statistic was calculated [32]. A Bonferroni correction was applied. The number of observations was (12). Hence, the statistical significance was kept at $p<0.004$.

\section{Results}

Out of 421 subjects, 277 (65.8\%) were women and the mean age of the participants was $71.9 \pm 6.7$ years. Demographic characteristics of the participants are tabulated in Table 1 . Most of the participants (60.8\%) had only obtained primary and lower secondary education and were unmarried (44.4\%). The majority of the elderly people engaged in both solitary leisure (86.9\%) and social (82.4\%) activities. The majority of the participants were minimally active $(63.4 \%)$ and only $16.4 \%$ had HEPA levels. The mean score of the MMSE was 22.9 \pm 4.9 . MMSE score ranged between 15 and 30. In our sample, 64.1\% had chronic diseases; $12.8 \%$ had respiratory disorders, $32.1 \%$ had hypertension and cardiovascular disorders, $1 \%$ had gastrointestinal disorders, $4 \%$ had musculoskeletal disorders, $18.3 \%$ had diabetes mellitus, $17.8 \%$ had urinary disorders and $5.5 \%$ had other medical disorders.

\section{Associations of MMSE}

Table 2 presents the associations between variables. The factors which had significant associations with cognition were; physical activity level, educational status, marital status, reason for attending the facility, visits by family members, engagement in solitary leisure activities and participation in social activities $(p<0.004)$.

The level of cognition was not associated with other factors, such as age, gender, BMI, presence of diseases, presence of sleep disturbances and sleep duration at night $(p>0.004)$. Though marital status and reason for arrive at the facility were associated factors for cognition among women, this was not observed among men. Those who were married had a significantly higher MMSE score than unmarried and divorced/widowed/ separated participants. Those who had HEPA level had a significantly higher MMSE score than inactive and minimally active elderly people. When leisure and social activity types were considered, those who engaged in physical and mental solitary leisure activities had a significantly higher MMSE score than their counterparts $(p<0.001)$ but we did not observe this significant difference between those who engaged in recreational and productive solitary activities and those who did not $(p>$ 0.004). Further, those who had social interactions, participated in activity groups, voluntary work and community related organizations had a significantly higher MMSE score than their counterparts $(p<0.001)$.

We included the associated variables, namely educational status, marital status, reason for attending the facility, visits by family members, engagement in solitary leisure activities, participation in social activities and physical activity level, in the regression analysis. Correlations between variables are shown in Table 3. Predictors of cognition in regression model are tabulated in Table 4. The same variables were entered to regression analysis for women but in men marital status and reason for attending the facility were excluded as they were not associated variables.

About $51.3 \%$ of variance in cognition was explained by the observed following variables; physical activity level, visits by family members, educational status and engaging in solitary leisure activities. In male participants, $41.2 \%$ of variance in cognition was explained by the variables such as physical activity level and educational status while in women $54.3 \%$ of variance in cognition was explained by the variables such as physical activity level, educational status, visits by family members and engaging in leisure activities.

\section{Discussion}

With population ageing, the number of people living with dementia is in an upward trend and it is expected to continue to escalate in low and middle income countries. As dementia is not an inevitable consequence of ageing, life style factors might modify the risk of dementia. It was calculated that more than a third of cases of dementia might be preventable theoretically by eliminating most potent 
Table 1 Demographic characteristics of the participants

\begin{tabular}{|c|c|c|c|}
\hline \multirow[t]{2}{*}{ Characteristic } & \multicolumn{3}{|l|}{ Percentage (\%) } \\
\hline & All elderly people $(n=421)$ & Female $(n=277)$ & Male $(n=144)$ \\
\hline Age, $\leq 70$ years & $180(42.8)$ & $129(46.6)$ & $51(35.4)$ \\
\hline \multicolumn{4}{|l|}{ Education } \\
\hline Primary and lower secondary education & $256(60.8)$ & $174(62.8)$ & $82(56.9)$ \\
\hline Upper secondary and higher Education & $165(39.2)$ & $103(37.2)$ & $62(43.1)$ \\
\hline \multicolumn{4}{|l|}{ Marital status } \\
\hline Married & $131(31.1)$ & $80(28.9)$ & $51(35.4)$ \\
\hline Unmarried & $187(44.4)$ & $122(44.0)$ & $65(45.1)$ \\
\hline Divorced/Separated/Widowed & $103(24.5)$ & $75(27.1)$ & $28(19.4)$ \\
\hline \multicolumn{4}{|l|}{ BMl } \\
\hline Underweight & $106(25.2)$ & $64(23.1)$ & $42(29.2)$ \\
\hline Normal BMI & $164(39.0)$ & $101(36.5)$ & $63(43.8)$ \\
\hline Overweight & $110(26.1)$ & $79(28.5)$ & $31(21.5)$ \\
\hline Obesity & $41(9.7)$ & $33(11.9)$ & $8(5.6)$ \\
\hline \multicolumn{4}{|l|}{ Reason to arrive to the facility } \\
\hline By their own free will & $143(34.0)$ & $96(34.7)$ & $47(32.6)$ \\
\hline Compelled to come & $278(66.0)$ & $181(65.3)$ & $97(67.4)$ \\
\hline Visits by family members, Visited & $240(57.0)$ & $159(57.4)$ & $81(56.3)$ \\
\hline Presence of chronic diseases, Present & $270(64.1)$ & $183(66.1)$ & $87(60.4)$ \\
\hline \multicolumn{4}{|l|}{ Engagement in solitary leisure activities } \\
\hline Engage & $366(86.9)$ & $241(87.0)$ & $125(86.8)$ \\
\hline Engage in mental activities & $227(53.9)$ & $154(55.6)$ & $73(50.7)$ \\
\hline Engage in physical activities & $162(38.5)$ & $101(36.5)$ & $61(42.4)$ \\
\hline Engage in recreational activities & $178(42.3)$ & $107(38.6)$ & $71(49.3)$ \\
\hline Engage in productive activities & $44(10.5)$ & $35(12.6)$ & $9(6.3)$ \\
\hline \multicolumn{4}{|l|}{ Social activity participation } \\
\hline Engage & $347(82.4)$ & $226(81.6)$ & $121(84.0)$ \\
\hline Have social interactions & $319(75.8)$ & $203(73.3)$ & $116(80.6)$ \\
\hline Engage in activity groups & $186(44.2)$ & $123(44.4)$ & $63(43.8)$ \\
\hline Perform voluntary work & $47(11.2)$ & $27(9.7)$ & $20(13.9)$ \\
\hline Participate in community organizations & $28(6.7)$ & $26(9.4)$ & $2(1.4)$ \\
\hline Sleep duration at night, $\leq 6 \mathrm{~h}$ & $209(49.6)$ & $126(45.5)$ & $83(57.6)$ \\
\hline Sleep disturbances, Present & $258(61.3)$ & $173(62.5)$ & $85(59.0)$ \\
\hline \multicolumn{4}{|l|}{ Physical activity level } \\
\hline Inactive & $85(20.2)$ & $59(21.3)$ & $26(18.1)$ \\
\hline Minimally active & $267(63.4)$ & $168(60.6)$ & $99(68.8)$ \\
\hline Health enhancing physical activity & $69(16.4)$ & $50(18.1)$ & 19 (13.2) \\
\hline
\end{tabular}

factors for dementia. However, available evidence has focused on high income countries and less evidence is available from low and middle income countries [6]. In this study, we aimed to identify the associated factors of cognition of elderly people living in residential care facilities for aged, as the demand for long term care of elderly is increasing [33].
In our study, the majority were female, had obtained only primary and lower secondary education and were unmarried. The sample has more females due to the fact that females live longer than men [34]. In Sri Lanka, the life expectancy of females is longer (75.8 for females and 71.2 for males in 2000) than men [2]. Most of the participants had engaged 
Table 2 Associations between MMSE score and selected variables

\begin{tabular}{|c|c|c|c|c|c|c|}
\hline \multirow[t]{2}{*}{ Factor } & All elderly & \multirow[t]{2}{*}{$p$} & Female & \multirow[t]{2}{*}{$p$} & Male & \multirow[t]{2}{*}{$p$} \\
\hline & Mean (SD) & & Mean (SD) & & Mean (SD) & \\
\hline \multicolumn{7}{|l|}{ Educational status } \\
\hline Primary and lower secondary education & $21.3 \pm 4.6$ & \multirow[t]{2}{*}{$<0.001$} & $21.2 \pm 4.6$ & \multirow[t]{2}{*}{$<0.001$} & $21.6 \pm 4.6$ & \multirow[t]{2}{*}{$<0.001$} \\
\hline Upper secondary, Advanced level and higher education & $25.4 \pm 4.3$ & & $25.4 \pm 4.6$ & & $25.3 \pm 3.9$ & \\
\hline \multicolumn{7}{|l|}{ Visits by family members } \\
\hline Visited & $24.0 \pm 4.5$ & \multirow[t]{2}{*}{$<0.001$} & $23.9 \pm 4.6$ & \multirow[t]{2}{*}{$<0.001$} & $24.4 \pm 4.3$ & \multirow[t]{2}{*}{$<0.001$} \\
\hline Did not visit & $21.4 \pm 5.1$ & & $21.3 \pm 5.2$ & & $21.6 \pm 4.8$ & \\
\hline \multicolumn{7}{|l|}{ Reason to arrive to the facility } \\
\hline By their own free will & $23.9 \pm 4.8$ & \multirow[t]{2}{*}{0.002} & $24.1 \pm 4.8$ & \multirow[t]{2}{*}{0.001} & $23.6 \pm 4.9$ & \multirow[t]{2}{*}{0.45} \\
\hline Compelled to come & $22.4 \pm 4.9$ & & $22.1 \pm 5.0$ & & $22.9 \pm 4.6$ & \\
\hline \multicolumn{7}{|l|}{ Engagement in solitary leisure activities } \\
\hline Engage & $23.5 \pm 4.8$ & \multirow[t]{2}{*}{$<0.001$} & $23.5 \pm 4.8$ & \multirow[t]{2}{*}{$<0.001$} & $23.6 \pm 4.7$ & \multirow[t]{2}{*}{0.001} \\
\hline Do not engage & $18.8 \pm 3.9$ & & $18.2 \pm 4.1$ & & $19.9 \pm 3.4$ & \\
\hline \multicolumn{7}{|l|}{ Social activity participation } \\
\hline Engage & $23.6 \pm 4.7$ & \multirow[t]{2}{*}{$<0.001$} & $23.6 \pm 4.8$ & \multirow[t]{2}{*}{$<0.001$} & $23.8 \pm 4.5$ & \multirow[t]{2}{*}{$<0.001$} \\
\hline Do not engage & $19.5 \pm 4.4$ & & $19.4 \pm 4.5$ & & $19.6 \pm 4.3$ & \\
\hline \multicolumn{7}{|l|}{ Marital status } \\
\hline Married & $24.8 \pm 4.6$ & \multirow[t]{3}{*}{$<0.001$} & $24.7 \pm 4.6$ & \multirow[t]{3}{*}{$<0.001$} & $24.8 \pm 4.6$ & \multirow[t]{3}{*}{0.005} \\
\hline Unmarried & $22.1 \pm 4.9$ & & $22.1 \pm 5.1$ & & $21.9 \pm 4.5$ & \\
\hline Divorced/Separated/Widowed & $22.1 \pm 4.7$ & & $21.8 \pm 4.8$ & & $22.9 \pm 4.4$ & \\
\hline \multicolumn{7}{|l|}{ Physical activity level } \\
\hline Inactive & $17.0 \pm 2.5$ & \multirow[t]{3}{*}{$<0.001$} & $17.1 \pm 2.6$ & $<0.001$ & $16.8 \pm 2.3$ & $<0.001$ \\
\hline Minimally active & $23.6 \pm 4.2$ & & $23.3 \pm 4.4$ & & $24.1 \pm 3.9$ & \\
\hline Health enhancing physical activity & $27.5 \pm 2.3$ & & $27.8 \pm 1.8$ & & $26.7 \pm 3.1$ & \\
\hline
\end{tabular}

*SD-Standard deviation

in solitary leisure and social activities and were minimally active. There were several factors that associated with the level of cognition such as physical activity level, educational status, marital status, reason for attending the facility, visits by family members and engagement in social and leisure activities. Among them only the factors such as physical activity level, visits by family members, educational status and engaging in leisure activities were the predictors of cognition in regression model.

Variables affecting the cognition have been different in other studies [21, 35-38]. Among different sociodemographic factors only educational achievements significantly associated with cognitive disorder while other factors such as age, gender, employment history, ethnicity, marital status did not in a Malaysian study [35]. In

Table 3 Correlation between variables

\begin{tabular}{|c|c|c|c|c|c|c|c|c|}
\hline & MMSE & $\begin{array}{l}\text { Educational } \\
\text { status }\end{array}$ & $\begin{array}{l}\text { Reason to arrival } \\
\text { to facility }\end{array}$ & $\begin{array}{l}\text { Social activity } \\
\text { participation }\end{array}$ & $\begin{array}{l}\text { Engagement in } \\
\text { leisure activities }\end{array}$ & $\begin{array}{l}\text { Visits by family } \\
\text { members }\end{array}$ & $\begin{array}{l}\text { Physical } \\
\text { activity level }\end{array}$ & $\begin{array}{l}\text { Marital } \\
\text { status }\end{array}$ \\
\hline MMSE & 1.000 & & & & & & & \\
\hline Educational status & .399 & 1.000 & & & & & & \\
\hline Reason to arrival to facility & -.150 & -.071 & 1.000 & & & & & \\
\hline Social activity participation & -.325 & -.051 & .186 & 1.000 & & & & \\
\hline Engagement in leisure activities & -.323 & -.109 & .144 & .321 & 1.000 & & & \\
\hline Visits by family members & -.266 & -.108 & .086 & .204 & .176 & 1.000 & & \\
\hline Physical activity level & .654 & .325 & -.128 & -.291 & -.232 & -.128 & 1.000 & \\
\hline Marital status & -.213 & -.144 & .051 & .151 & .073 & .052 & -.249 & 1.000 \\
\hline
\end{tabular}


Table 4 Associated variables of cognition

\begin{tabular}{|c|c|c|c|c|c|c|}
\hline & & Determinant & Standardized Beta coefficient & $p$ & Adjusted $R^{2}$ & $\mathrm{~F}$ \\
\hline \multirow[t]{5}{*}{ All elderly people } & MMSE score & Physical activity level & 0.54 & $<0.001^{* *}$ & 0.513 & 111.45 \\
\hline & & Educational status & 0.19 & $<0.001^{* *}$ & & \\
\hline & & Visits by family members & -0.15 & $<0.001^{* *}$ & & \\
\hline & & Engaging in leisure time activities & -0.15 & $<0.001^{* *}$ & & \\
\hline & & Constant & & $<0.001^{* *}$ & & \\
\hline \multirow[t]{5}{*}{ Female } & MMSE score & Physical activity level & 0.55 & $<0.001^{* *}$ & 0.543 & 83.09 \\
\hline & & Educational status & 0.20 & $<0.001^{* *}$ & & \\
\hline & & Visits by family members & -0.17 & $<0.001^{* *}$ & & \\
\hline & & Engaging in leisure time activities & -0.17 & $<0.001^{* *}$ & & \\
\hline & & Constant & & $<0.001^{* *}$ & & \\
\hline \multirow[t]{3}{*}{ Male } & MMSE score & Physical activity level & 0.55 & $<0.001^{* *}$ & 0.412 & 51.10 \\
\hline & & Educational status & 0.21 & $0.002^{* *}$ & & \\
\hline & & Constant & & $<0.001^{* *}$ & & \\
\hline
\end{tabular}

*Significance value $p<0.004$; **

a South African study, those who were at younger age, who were married, who gained secondary level education or higher, who had moderate or high physical activity level had higher cognitive functioning [36]. In an Indian study, cognitive impairment was more likely to be among those who were old-old, who were illiterate and were widowed [37]. In a Brazilian study, those who had systemic arterial hypertension and those who had been institutionalized on their own will were found to be less likely to be cognitively impaired [38]. In Maroof et al., [21] study, age, gender, marital status and literacy level significantly associated with having cognitive impairment.

Age is a well-documented factor that affects cognition $[12,36,38]$ and it is the greatest non modifiable risk factor [6]. In two studies, age did not exert a significant influence on cognition [35, 39]. With bonferroni adjusted $p$ value $(p<0.004)$ in our study, we did not observe a significant difference in the cognition based on age but the association had a $\mathrm{p}$ value of 0.018 . Changes in the structure and function of the brain might correlate with these age-related cognitive changes [12]. Livingston et al., [6] suggested that age as a less powerful risk factor when it was taken into consideration with other comorbidities. Torres et al., [40] has shown that less education in early life depicts a much stronger influence than age for age related cognitive decline. Further, this is in line with previous findings in ageing Brazilian populations [41]. Hence, as our sample constituted of more elderly people with less education and as we have considered age with other comorbidities, we might have lost the significant impact of age on cognition.

We did not observe a statistically significant difference in cognition between males and females. Few studies mentioned significant difference in cognition based on gender [21, 22, 39] while many reported no significant difference [20, 35, 38]. Sex differences in cognitive ageing may be due to differences in brain structure and function [21].

In our study, educational status was a predictor of cognition in regression model for both males and females. Those who had obtained upper secondary, advanced level and higher education had significantly higher level of cognition than the other group. Similar findings were observed in three other studies saying that cognitive status significantly differed based on schooling [42-44]. A Malaysian study showed education attainment as the only sociodemographic factor that showed significant association with cognitive disorder [35]. Three possible mechanisms have explained for having lower rates of cognitive decline in elderly people with higher level of education. The first mechanism is that people with lower education have a higher risk of damage to central nervous system; second, people with higher education may have more neuronal reserve capacity; and third, people with higher education may have the ability to generate better strategies of compensation [45].

A Chinese study showed a higher chance of cognitive deterioration in elderly males who were single and widowed, compared to married, but this was not evidenced among women [14]. However, we observed this finding in opposite direction. We observed a significant difference in women but not in men and this might be due to considering bonferroni adjusted $p$ value $(p<$ 0.004 ) or females gaining more emotional stress by loss of their partner compared to males. Being married positively associated with cognition [36], while being widowed showed a higher probability of cognitive impairment [22, 37]. A higher prevalence of cognitive impairment was observed among elderly people who live 
without a partner in institutions [38]. Married elderly gain better mental conditions through sharing their life with a partner. Emotional stress in divorced or widowed people due to unexpected life events might negatively affect their cognition [35].

Data available on relationship between BMI and cognition is not consistent. Some studies suggest obese individuals are at a lower risk of cognitive impairment [46, 47] while others show overweight and obese individuals are known to be at a higher risk for dementia [48]. In our study, cognition did not significantly vary based on BMI similar to what Zhou et al., [49] had found. The association of cognition with BMI is bidirectional. It might be that either high or low BMI leading to cognitive impairment or vice versa.

In our study, those who chose to be admitted to facility as their wish had a higher level of cognition. It might be due to less psychological stress. Previous studies have shown psychological stress [50] was associated with increased risk of dementia. From our study, we cannot determine the cause and effect of whether voluntary admission improves cognition or those who had cognitive impairment were compelled to come to the care facilities. Past literature supports on both aspects. de Andrade et al., [38] depicted institutionalization by own choice as a protective factor for cognitive impairment. Pereira and Besse [51] found a higher level of functional independency among elderly who were self-institutionalized which will subsequently lead to better cognition. In contrast, a systemic review mentioned that those who had cognitive impairment had a higher chance of getting institutionalized and cognitive impairment was a predictor of institutionalization [25].

Elderly living in elderly homes experience loneliness. However, this depends on number of family visits. Further, elderly people in care facilities prefer if they are visited by their family members as frequently as possible [52]. In our study, those who were visited by family members had a higher level of cognition. It was a predictor of cognition among women in regression model. This might be due to lessening of the feeling of being isolated. Either visits by family members resulted in higher cognition or those who were cognitively impaired were not visited by family members cannot be determined by our study due to the nature of the study design. Social isolation is one of the risk factors for development of dementia [6], and loneliness [53] was associated with increased risk of dementia. Greater purpose in life [54] was associated with reduced risk of dementia. Nevertheless, individuals who were mentally and physically declined, who had impairments in cognition, were less likely to be visited by their family members [52].

Previous research has focused attention on different diseases which lead to cognitive decline $[6,38]$. The association of diabetes mellitus and mid-life hypertension with cognitive impairment has been previously observed [55, 56]. We did not observe a significant difference in the levels of cognition based on the types of diseases, such as diabetes mellitus, cardiovascular disorders and other disorders. It was hypothesized that anomalies in peripheral insulin cause decreased production of brain insulin which results in impairment of amyloid clearance which leads to impairment in cognition [57]. A review showed that diabetes increased the risk of conversion of mild cognitive impairment to dementia [58].

In recent decades, the attention on the protective role of leisure activities against the occurrence of dementia is increasing [59]. Paillard-Borg et al., [29] examined five types of leisure activities namely mental, social, physical, productive and recreational. We used this as the classification but we considered social activities as a separate entity. We found those who participated in solitary leisure activities had significantly higher level of cognition than those who do not participate. It was a predictor of cognition among women in regression model. When elaborated, those who participate in physical and mental solitary leisure activities had a significantly higher level of cognition than those who did not. According to Paillard-Borg et al., [29], there is an association between cognitive functioning and participation in mental, social and productive activities.

Physical leisure activities promotes physical engagement while mental leisure activities do mental stimulation which in turn improves cognition. Intellectual stimulation has been considered as a factor that enhance cognitive reserves [6]. The reason for not observing a significant difference in cognition in those who engaged in productive activities might be due to having a low proportion of participants in that category. As to Paillard-Borg et al., [29] productive activities are cognitively stimulating but recreational activities are less so [29]. This could be the reason for not observing a significant difference in cognition based on participation in recreational activities in our study.

We cannot determine whether poor cognition led to poor participation in leisure activities or vice versa. It was mentioned that participants with dementia were less active in mental, social and productive activities. They speculated it as either experiencing loneliness or living with dementia might prevent elderly people from being active in leisure activities [29]. In contrast, plenty of studies show the protective role of leisure activities on cognition [59-61]. The mechanism underlying the protective impact of leisure activities on cognition is still uncertain, a number of theories have been proposed. Krammer et al., [62] suggested that leisure activities make neurological processes efficient, adaptive and 
plastic which in turn would be helpful in coping with progressing cognitive decline in dementia. However, larger samples and long follow-up are required in order to confirm the protective role of leisure activities [59].

Social engagement reflects partaking different social activities and having social contacts [63]. Fu, Li and Mao [17] have categorized social activities into five groups i.e.; participating in community related organizations, voluntary work, hobby groups and sports groups and having connections with friends. These are the areas which we used for categorization. In our study, we merged participation in hobby groups and sports groups to one variable and it was named as participation in activity groups. Elderly people who participated in social activities had better cognition than those who did not. Elderly people who participated in voluntary work, had social interactions, participated in activity groups and community organizations had significantly higher level of cognition than those who did not.

It is uncertain whether cognitive decline is the cause of reduced socialization or vice versa [6]. On one direction, social activities reduce social isolation and thereby improve cognition [28] and it is potentially a modifiable risk factor [64]. On the other hand, it may be that subjects with cognitive impairment have poor participation in social activities but little evidence is available for reverse causation [65]. Recent evidence proposes that older people who are more socially engaged have a higher level of cognitive function $[17,64,66]$. Fu, $\mathrm{Li}$ and Mao have stated several possible explanations for the relationship between social activities and cognitive function [17]. Social activities may help to improve cognition by enabling more complex and compound thinking [67], maintaining or expanding the social network $[66,68]$ and providing a greater sense of purpose [69].

We did not observe a significant difference in cognition based on sleep duration and with bonferroni adjusted $p$ value, presence of sleep disturbances was not an associated factor. The relationship between sleep and cognition is bidirectional. Cognitive decline may lead to poor sleep or vice versa. Sleep disturbances significantly increase cognitive decline [70, 71]. It has been hypothesized that sleep deprivation aggravate the neuropathological processes leading to amyloid depositions [72, 73]. It has observed that alterations in sleep duration occur prior to the appearance of cognitive symptoms in Alzheimer's disease [74].

Physical activity is a cognitive reserve enhancing factor and physical inactivity is a cardiovascular risk factor for dementia [6]. We observed a significant difference in MMSE score among three physical activity groups which are inactive, minimally active and HEPA. Physical activity was a predictor of cognition in the regression model. The relationship between physical activity and cognition is bidirectional. One can argue, higher physical activity leads to higher cognition. Other might argue that higher cognition makes an individual more physically active. We cannot determine the cause and effect due to the cross sectional nature of the study, but it is more plausible to say that high physical activity levels lead to improvements in cognition [75-79]. Changes in hormone levels, improvement in cerebral blood flow and an increase in number of neuronal synapses, brain volume and plasticity are thought to be contributory in physiological benefits of physical activity [10]. A review of Lista and Sorrentino discussed on supramolecular and molecular mechanisms of how physical activity prevents cognitive decline. These two biological mechanisms included neurogenesis or neural cell proliferation, synaptogenesis, angiogenesis and the role of brain-derived neurotrophic factor (BDNF) [80].

The cognitive abilities which persist steady, get worse or get advance with age will depend on the health of the brain and body. Further, skills that we are practicing in our day to day lives will also contribute for it [81]. Livingston et al., [6] suggested that $35 \%$ of dementia is due to a combination of nine risk factors. They had mentioned having midlife hypertension and obesity, having hearing loss, having depression in late life, smoking, having diabetes, being physically inactive, being educated to a maximum of 11-12 years and being socially isolated as risk factors. In our study, physical activity level, educational status, visits by family members and engaging in leisure time activities were the predictors in regression model with $51.3 \%$ of the variance. Other factors that have not been followed or are unexplained in the study may have contributed to the remainder of the variance in the cognition, for which further investigations are necessary. Some of the factors that Livingston et al., [6] mentioned were not investigated in our study but in both physical activity and educational status are mentioned. The associated factors for cognition in western countries might be different from Asian countries. Further, associated factors for cognition in elderly people in aged care facilities will be different from community dwelling elderly people as their living arrangements are different. As a result of population ageing, demand for long term care has increased [33], and hence it might be worthwhile to investigate these factors to establish prevention strategies.

Already, cognitive stimulating lifestyles have been identified as reducing cognitive deterioration. Among them, cognitive training, physical activity, social engagement and nutrition play a vital role [82]. Currently, available literature suggests the importance of magnesium [83] to reduce cognitive deterioration. A meta-analysis suggested that vitamin $\mathrm{D}$ deficiency increases the risk of cognitive impairment [84]. Dickens et al., [85] mentioned, though cross 
sectional studies had proved the association between vitamin $\mathrm{D}$ and cognitive decline, no prospective studies are available and they recommend further studies. Durga et al., [86] had shown that folic acid supplementation for 3 years, significantly improved cognitive function. Physical activities such as Tie chi exercises have shown positive effects on cognitive functions [87]. Hanna-Pladdy and MacKay suggested a strong predictive effect of high musical activity throughout the life on preservation of cognitive functioning in advanced age [88]. Working on cognitive stimulating activities such as crossword puzzles has been associated with preservation of cognition in older adults [89]. Further, depression has been proposed to be a risk factor for dementia [90]. In our study, we excluded elderly people who had diagnosed as having depression. However, treating depression might be useful to improve cognition of elderly people via treatment with antidepressants [90]. If a person can delay the onset of dementia, that leads to have a more fulfilling life for a longer duration with less time suffering from dementia [91]. In other studies as well as in our study, we found participation in physical activities, social and leisure activities as associated factors of cognitive decline. Hence, it may be beneficial to address these in elderly people living in care facilities and encourage them in participation in physical, social and leisure activities.

\section{Strengths and limitations}

This study provides evidence on associated factors for cognition of elderly people living in residential care facilities for aged in Sri Lanka, which is an Asian country as well as a lower middle income country. We had several limitations. One is our study was cross sectional in nature so we cannot determine the cause and effect. There were some reviews on some aspects to identify direction of the relationship but on some aspects it was not for example; visits by family members. Minimal MMSE score in our sample was 15 and this might be due to inclusion of only physically independent elderly people. Memory problems and recall bias might have affected on reliability of the answers. We recommend interventional or case control studies to confirm these findings.

\section{Conclusion}

Though there were several factors that associated with the level of cognition such as physical activity level, educational status, marital status, reason for attending the facility, visits by family members, participation in social activities, engagement in solitary leisure activities, only the factors such as physical activity, visits by family members, educational status, engaging in solitary leisure activities were the predictors of cognition. These factors need to be addressed in caring for elderly people in care facilities.

\section{Abbreviations}

ANOVA: Analysis of Variance; BDNF: Brain-Derived neurotrophic factor; HEPA: Health enhancing physical activity; IPAQ-E: International physical activity questionnaire-elderly; MMSE: Mini Mental State Examination; SD: Standard Deviation; SPSS: Statistical Package for Social Sciences; VIF: Variance inflation factor

\section{Acknowledgements}

I would like to acknowledge, Prof. Bilesha Perera, Department of Community Medicine, Faculty of Medicine, University of Ruhuna for providing me statistical support.

\section{Funding}

University of Sri Jayewardenepura research Grant (ASP/01/RE/SCI/2015/36).

\section{Availability of data and materials}

The datasets used and analyzed during the current study are available from the corresponding author on reasonable request.

\section{Authors' contributions}

MWKG was involved in designing the study, collection of data, preparing the data base, statistical analysis of data, interpretation of data and writing the first draft of the manuscript. DCH was involved in designing the study, obtaining funding, interpretation of data, critical analysis of results, manuscript writing, drafting the manuscript, final proof reading before submission and supervision of progress of the study. KDP was involved in designing the study, interpretation of data, critical analysis of results, final proof reading before submission, manuscript writing, drafting the manuscript and supervision of progress of the study. All authors read and approved the final manuscript.

\section{Ethics approval and consent to participate}

Ethical approval was obtained from the Ethics Review Committee, Faculty of Medical Sciences, University of Sri Jayewardenepura, Gangodawila, Nugegoda, Sri Lanka (Ref No. 24/15) and informed written consent was obtained from all the participants individually and in cases of individuals lacking capability to provide consent, it was obtained from their legal guardians.

\section{Consent for publication}

Not Applicable.

\section{Competing interests}

The authors declare no competing interests with respect to the research, authorship, and publication of this article.

\section{Publisher's Note}

Springer Nature remains neutral with regard to jurisdictional claims in published maps and institutional affiliations.

\section{Author details}

${ }^{1}$ Department of Nursing, Faculty of Allied Health Sciences, University of Ruhuna, Galle, Sri Lanka. ${ }^{2}$ Department of Physiology, Faculty of Medical Sciences, University of Sri Jayewardenepura, Gangodawila, Nugegoda, Sri Lanka. ${ }^{3}$ Department of Medicine, Faculty of Medicine, University of Ruhuna, Galle, Sri Lanka.

Received: 22 May 2018 Accepted: 26 December 2018

Published online: 08 January 2019

References

1. Soósová MS. Determinants of quality of life in the elderly. Cent Eur J Nurs Midw. 2016;7(3):484-93.

2. Siddhisena KAP. Soci-economic implications of ageing in Sri Lanka : an overview. Oxford Institute of Ageing; 2005. Working paper number WP 105.

3. World Health Organization World report on ageing and health. World Health Organization; 2015; 1-246.

4. Alzheimer's Disease International. The global impact of dementia 20132050: policy brief for heads of Government. London: Alzheimer's Disease International; 2013.

5. World Health Organization. Draft global action plan on the public health response to dementia. Seventeenth world health assembly; 2017. 
6. Livingston G, Sommerlad A, Orgeta V, Costafreda SG, Huntley J, Ames D, et al. Dementia prevention, intervention, and care. Lancet. 2017. https://doi. org/10.1016/S0140-6736(17)31363-6.

7. Neisser U. Cognitive psychology. New York: Appleton-century-crofts; 1967. Cited by Posner MI, Bourke P, cognitive psychology. Am J Psychol. 1993; 105(4):621-6.

8. Bakos DS, Couto MCPDP, Melo W, Parente MADMP, Koller SH, Bizzaro L. Executive functions in the young elderly and oldest old: a preliminary comparison emphasizing decision making. Psychol Neurosci. 2008;1(2):183-9.

9. Williams K, Kemper S. Exploring interventions to reduce cognitive decline in aging. J Psychosoc Nurs Ment Health Serv. 2010;48(5):42-51.

10. Colcombe SJ, Erickson Kl, Scalf PE, Kim JS, Prakash R, McAuley E, et al. Aerobic exercise training increases brain volume in aging humans. J Gerontol Med Sci. 2006;61A:1166-70.

11. Smith PJ, Potter GG, McLaren ME, Blumenthal JA. Impact of aerobic exercise on neurobehavioral outcomes. Ment Health Phys Act. 2013;6(3):139-53.

12. Murman DL. The impact of age on cognition. Semin Hear. 2015;36(3):11121. https://doi.org/10.1055/s-0035-1555115.

13. Wilson RS, Hebert LE, Scherr PA, Barnes LL, de Leon CFM, Evans DA. Educational attainment and cognitive decline in old age. Neurology. 2009; 72(5):460-5.

14. Feng L, Ng X, Yap P, Li J, Lee L, Håkansson K, et al. Marital status and cognitive impairment among community-dwelling Chinese older adults: the role of gender and social engagement. Dement Geriatr Cogn Dis Extra. 2014:4(3):375-84

15. Jung MS, Kim H, Lee Y, Kim M, Chung E. Different effects of cognitive and nonexercise physical leisure activities on cognitive function by age in elderly korean individuals. Osong Public Health Res Perspect. 2017:8(5):308-317.

16. Iwasa I, Yoshida Y, Kai I, Suzuki T, Kim H, Yoshida H. Leisure activities and cognitive function in elderly community-dwelling individuals in Japan: a 5year prospective cohort study. J Psychosom Res. 2012;72(2):159-64.

17. Fu C, Li Z, Mao Z. Association between Social Activities and Cognitive Function among the Elderly in China: A Cross-Sectional Study. Int. J. Environ. Res. Public Health. 2018;15(231). https://doi.org/10.3390/ijerph15020231.

18. Rauchs G, Carrier J, Peigneux P. Sleep and cognition in the elderly. Frontiers in Neurology. 2013;4(71). https://doi.org/10.3389/fneur.2013.00071.

19. Munro CA, Winicki JM, Schretlen DJ, Gower EW, Turano KA, Muñoz B, et al. Sex differences in cognition in healthy elderly individuals. Neuropsychol Dev Cogn B Aging Neuropsychol Cogn. 2012;19(6):759-68.

20. McCarrey AC, An Y, Kitner-Triolo MH, Ferrucci L, Resnick SM. Sex differences in cognitive trajectories in clinically normal older adults. Psychol Aging. 2016;31(2):166-75.

21. Maroof M, Ahmad A, Khalique N, Ansari MA, Shah MS, Eram U, et al. Prevalence and determinants of cognitive impairment among rural elderly population of Aligarh. Ntl J Community Med. 2016;7(3):189-92.

22. Ferreira LS, Pinho MSP, Pereira MWM, Ferreira AP. Perfil cognitivode idosos residentes em Instituicoes de Longa Permanencia de Brasilia-DF. Revista Brasileira de Enfermagem. 2014;67(2):247-51 Brazilian.

23. Gamage MWK, Hewage C, Pathirana KD. Effect of cognitive and executive functions on perception of quality of life of cognitively normal elderly people dwelling in residential aged care facilities in Sri Lanka. BMC Geriatrics. 2018;18(256). https://doi.org/10.1186/s12877-018-0937-6.

24. Luppa M, Luck T, Weyerer S, König HH, Brähler E, Riedel-Heller SG. Prediction of institutionalization in the elderly; a systematic review. Age Ageing. 2010:39(1):31-8.

25. Folstein MF, Folstein SE, McHugh PR. "Mini-mental state". A practical method for grading the cognitive state of patients for the clinician. J Psychiatr Res. 1975;12(3):189-98.

26. Ham RJ, Sloane PD, Bernard MA, Flaherty E. Primary care geriatrics: a casebased approach, 5th edition. 2007;952, Mosby. Inc. Philadelphia. Pennsylvania.

27. World Health Organization Expert Consultation. Appropriate body-mass index for Asian populations and its implications for policy and intervention strategies. Lancet. 2004;363:157-63.

28. Adams KB, Leibbrandt $\mathrm{S}, \mathrm{Moon} \mathrm{H}$. A critical review of the literature on social and leisure activity and wellbeing in later life. Ageing \& Society. 2011;31: 683-712.

29. Paillard-Borg S, Wang H, Winblad B, Fratiglioni L. Pattern of participation in leisure activities among older people in relation to their health conditions and contextual factors : a survey in a Swedish urban area. Ageing \& Society. 2009;29:803-21.
30. Chang P, Wray L, Lin Y. Social relationships, leisure activity, and health in older adults. Health Psychol. 2014;33(6):516-23.

31. International Physical Activity Questionnaire. International physical activity questionnaire - cultural adaptation; 2009. [Accessed 20 June 2018]. Available from: https://sites.google.com/site/theipaq/scoring-protocol.

32. Field AP. Discovering statistics using SPSS: (and sex and drugs and rock ' $n$ ' roll). 3rd ed. Los Angeles: SAGE Publications; 2009.

33. Böckerman $P$, Johansson E, Saarni S. Institutionalisation and quality of life for elderly people in Finland, Enepri research report no. 92, European Network of Economic Policy Research Institutes; 2011.

34. Beckert M, Irigaray TQ, Trentini CM. Quality of life, cognition and performance of executive functions in the elderly. Studies of Psychology (Campinas). 2012;29(2):155-62.

35. Mei JWZ, Maung TM, Mallick KK. The prevalence of cognitive disorder and its associated sociodemographic factors in elderly from assisted living residences. Klang Valley Malaysia. 2016;15(4):109-14.

36. Peltzer K, Phaswana-Mafuya N. Cognitive functioning and associated factors in older adults in South Africa. S Afr J Psych. 2012;18(4):157-63.

37. Sharma D, Mazta SR, Parashar A. Prevalence of cognitive impairment and related factors among elderly: a population-based study. Journal of Dr. NTR University of Health Sciences. 2013:2(3):171-6.

38. de Andrade FLJP, de Lima JMR, Fidelis KNM, Jerez-Roig J, de Lima KC. Cognitive impairment and associated factors among institutionalized elderly persons in Natal, Rio Grande do Norte, Brazil. Rev. bras. Geriatr. Gerontol. Rio de Janeiro. 2017;20(2):186-96.

39. De Silva R, Disanayaka S, De Zoysa N, Sanjeewanie N, Somaratne S, Foster J, et al. Norms for the mini-mental state examination from a sample of Sri Lankan older people. Int J Geriatr Psychiatry. 2009:24:666-70.

40. NVO B-T, Bento-Torres J, Tomás AM, Costa VO, PGR C, CNM C, et al. Influence of schooling and age on cognitive performance in healthy older adults. Brazilian Journal of Medical and Biological Research. 2017;50(4): e5892. https://doi.org/10.1590/1414-431X20165892.

41. de Azeredo Passos VM, Giatti L, Bensenor I, Tiemeier H, Ikram MA, de Figueiredo RC, et al. Education plays a greater role than age in cognitive test performance among participants of the Brazilian longitudinal study of adult health (ELSA-Brasil). BMC Neurol. 2015;15:191. https://doi.org/10.1186/ s12883-015-0454-6.

42. Pereira RN, Pontes MDLF, Silva AO, Monteiro ED, Da Silva CR, Silva LM, et al. Quality of life and the cognitive condition of elderly served in family health unit. Int Arch Med. 2015;8(225):1-9.

43. Converso MER, lartelli I. Caracterizacao e analise do estado mental efuncional de idosos institucionalizados eminstituicoes publicas de longa permanencia. J Bras Psiquiatr. 2007;56(4):267-72 Brazilian.

44. Machado JC, Ribeiro RDCL, Cotta RMM, PFG L. Declinio cognitivo de idosos e sua associacao com fatores epidemiologicos em Vicosa. Minas Gerais. Rev. bras. geriatr. gerontol. 2011;14(1):109-2 Brazilian

45. Leibovici D, Ritchie K, Ledesert B, Touchon J. Does education level determine the course of cognitive decline? Age Ageing. 1996;25:392-7.

46. Kim S, Kim Y, Park SM. Body Mass Index and Decline of Cognitive Function. PLOS one. 2016;11(2). https://doi.org/10.1371/journal.pone.0148908.

47. Xiang $X, A n$ R. Body weight status and onset of cognitive impairment among U.S. middle-aged and older adults. Arch Gerontol Geriatr. 2015;60(3):394-400.

48. Prickett C, Brennan L, Stolwyk R. Examining the relationship between obesity and cognitive function: a systematic literature review. Obes Res Clin Pract. 2015;9(2):93-113.

49. Zhou Y, Flaherty JH, Huang C, Lu Z, Dong B. Association between body mass index and cognitive function among Chinese nonagenarians/ centenarians. Dement Geriatr Cogn Disord. 2010;30:517-24.

50. Johansson L, Guo X, Waern M, Östling S, Gustafson D, Bengtsson C, et al. Midlife psychological stress and risk of dementia: a 35-year longitudinal population study. Brain. 2010;133:2217-24.

51. Pereira F, Besse M. Factors associated with the functional independence of elderly residents in a long-term institution. Acta Fisiátrica. 2011;18(2):66-70.

52. Gurung S, Ghimire S. Role of family in elderly care. In: Undergraduate: Lapland University of Applied Sciences; 2014.

53. Wilson RS, Barnes LL, Aggarwal NT, Boyle PA, de Leon MCFE HLE, et al. Cognitive activity and the cognitive morbidity of Alzheimer disease. Neurology. 2010;75:990-6.

54. Boyle PA, Buchman AS, Barnes LL, Bennett DA. Effect of a purpose in life on risk of incident Alzheimer disease and mild cognitive impairment in community-dwelling older persons. Arch Gen Psychiatry. 2010;67:304-10. 
55. Walker KA, Power MC, Gottesman RF. Defining the relationship between hypertension, cognitive decline, and dementia: a review. Curr Hypertens Rep. 2017;19(3):24

56. Hassing LB, Grant MD, Hofer SM, Pedersen NL, Nilsson SE, Berg S, et al. Type 2 diabetes mellitus contributes to cognitive decline in old age: a longitudinal population-based study. J Int Neuropsychol Soc. 2004;10(4): 599-607.

57. Yaffe K. Metabolic syndrome and cognitive disorders: is the sum greater than its parts? Alzheimer Dis Assoc Disord. 2007;21:167-71.

58. Cooper C, Sommerlad A, Lyketsos C, Livingston G. Modifiable predictors of dementia in mild cognitive impairment: a systematic review and metaanalysis. Am J Psychiatr. 2015;172(4):323-34.

59. Wang HX, Xu W, Pei JJ. Leisure activities, cognition and dementia. Biochim Biophys Acta. 2012 Mar;1822(3):482-91.

60. Verghese J, Lipton RB, Katz MJ, Hall CB, Derby CA, Kuslansky G, et al. Leisure activities and the risk of dementia in the elderly. N Engl J Med. 2003;348: 2508-16.

61. Wang $H$, Jin $Y$, Hendrie HC, Liang C, Yang L, Cheng Y, et al. Late life leisure activities and risk of cognitive decline. J Gerontol A Biol Sci Med Sci. 2013; 68(2):205-13.

62. Kramer AF, Bherer L, Colcombe SJ, Dong W, Greenough WT. Environmental influences on cognitive and brain plasticity during aging. J Gerontol A Biol Sci Med Sci. 2004;59:M940-57.

63. Bassuk SS, Glass TA, Berkman LF. Social disengagement and incident cognitive decline in community-dwelling elderly persons. Ann Intern Med. 1999;131(3):165-73.

64. James BD, Wilson RS, Barnes LL, Bennett DA. Late-life social activity and cognitive decline in old age. J Int Neuropsychol Soc. 2011;17(6):998-1005.

65. Barnes LL, Mendes de Leon CF, Wilson RS, Bienias JL, Evans DA. Social resources and cognitive decline in a population of older African Americans and whites. Neurology. 2004;63(12):2322-6.

66. Fratiglioni L, Wang HX, Ericsson K, Maytan M, Winblad B. Influence of socia network on occurrence of dementia: a community-based longitudinal study. Lancet. 2000;355:1315-9.

67. Karp A, Paillard-Borg S, Wang H-X, Silverstein M, Winblad B, Fratiglioni L. Mental, physical, and social components in leisure activities equally contributes to decrease dementia risk. Dement Geriatr Cogn Disord. 2006; 21(2):65-73.

68. Hsu HC. Does social participation by the elderly reduce mortality and cognitive impairment? Aging Ment Health. 2007;11:699-707.

69. Fratiglioni L, Paillard-Borg S, Windblad B. An active and socially integrated lifestyle in late life might protect against dementia. Lancet Neurol. 2004;3: $343-53$

70. Hot P, Rauchs G, Bertran F, Denise P, Desgranges B, Clochon P, et al. Changes in sleep theta rhythm are related to episodic memory impairment in early Alzheimer's disease. Biol Psychol. 2011;87:334-9.

71. Westerberg CE, Mander BA, Florczak SM, Weintraub S, Mesulam MM, Zee PC, et al. Concurrent impairments in sleep and memory in amnestic mild cognitive impairment. J Int Neuropsychol Soc. 2012;18:490-500.

72. Kang JE, Lim MM, Bateman RJ, Lee JJ, Smyth LP, Cirrito JR, et al. Amyloidbeta dynamics are regulated by orexin and the sleep-wake cycle. Science. 2009;326:1005-7

73. Ju YE, McLeland JS, Toedebusch CD, Xiong C, Fagan AM, Duntley SP, et al. Sleep quality and preclinical Alzheimer disease. JAMA Neurol. 2013. https:// doi.org/10.1001/jamaneurol.2013.2334

74. Ju YE, Lucey BP, Holtzman DM. Sleep and Alzheimer disease pathology - a bidirectional relationship. Nat Rev Neurol. 2014;10:115-9.

75. Smith PJ, Blumenthal JA, Hoffman BM, Cooper H, Strauman TA, Welsh-Bohmer $K$, et al. Aerobic exercise and neurocognitive performance: a meta-analytic review of randomized controlled trials. Psychosom Med. 2010;72(3):239-52.

76. Busse AL, Gil G, Santarém JM, Filho WJ. Physical activity and cognition in the elderly: a review. Dementia \& Neuropsychologia. 2009:3(3):204-8.

77. Bherer L, Erickson Kl, Liu-Ambrose T. A Review of the Effects of Physical Activity and Exercise on Cognitive and Brain Functions in Older Adults. Journal of Aging Research. 2013:657508. https://doi.org/10.1155/2013/ 657508

78. Colcombe S, Kramer AF. Fitness effects on the cognitive function of older adults: a meta-analytic study. Psychol Sci. 2003:14(2):125-30.

79. Sofi F, Valecchi D, Bacci D, Abbate R, Gensini GF, Casini A, et al. Physical activity and risk of cognitive decline: a meta-analysis of prospective studies. J Intern Med. 2011;269(1):107-17.
80. Lista I, Sorrentino G. Biological mechanisms of physical activity in preventing cognitive decline. Cell Mol Neurobiol. 2010;30(4):493-503.

81. Mather M. Aging and cognition. WIREs Cogn Sci. 2010;1:346-62.

82. Williams KN, Kemper S. Interventions to reduce cognitive decline in aging. J Psychosoc Nurs. 2010;48(5):42-51.

83. Liu G, Weingera JG, Lub Z, Xue F, Sadeghpoura S. Efficacy and safety of MMFS-01, a synapse density enhancer, for treating cognitive impairment in older adults: a randomized, double-blind. Placebo-Controlled Trial Journal of Alzheimer's Disease. 2016:49:971-90.

84. Etgen T, Sander D, Bickel H, Sander K, Förstl H. Vitamin D deficiency, cognitive impairment and dementia: a systematic review and meta-analysis. Dement Geriatr Cogn Disord. 2012;33(5):297-305.

85. Dickens AP, Lang IA, Langa KM, Kos K, Llewellyn DJ. Vitamin D, cognitive dysfunction and dementia in older adults. CNS Drugs. 2011;25(8):629-39.

86. Durga J, Van Boxtel M, Shouten E, et al. Effect of 3 year folic acid supplementation on cognitive function in older adults in the FACIT trial: a randomised double blind controlled trial. Lancet. 2007;369(9557):208-16.

87. Wu Y, Wang Y, Burgessa EO, Wu J. The effects of tai chi exercise on cognitive function in older adults: a meta-analysis. J Sport Health Sci. 2013; 2(4):193-203.

88. Hanna-Pladdy B, MacKay A. The relation between instrumental musical activity and cognitive aging. Neuropsychology. 2011:25(3):378-86.

89. Mireles DE, Charness N. Computational explorations of the influence of structured knowledge on age-related cognitive decline. Psychol Aging. 2002;17(2):245-59.

90. Muliyala KP, Varghese M. The complex relationship between depression and dementia. Ann Indian Acad Neurol. 2010;13(Supp 12):S69-73.

91. Larson EB. Prospects for delaying the rising tide of worldwide, late-life. Int Psychogeriatr. 2010;22(8):1196-202.
Ready to submit your research? Choose BMC and benefit from:

- fast, convenient online submission

- thorough peer review by experienced researchers in your field

- rapid publication on acceptance

- support for research data, including large and complex data types

- gold Open Access which fosters wider collaboration and increased citations

- maximum visibility for your research: over $100 \mathrm{M}$ website views per year

At $\mathrm{BMC}$, research is always in progress.

Learn more biomedcentral.com/submissions 